\title{
Medication-overuse headache: a review
}

This article was published in the following Dove Press journal:

Journal of Pain Research

26 June 2014

Number of times this article has been viewed

\section{Espen Saxhaug \\ Kristoffersen ${ }^{1-3}$ \\ Christofer Lundqvist ${ }^{1,2,4}$ \\ 'Research Centre, Akershus University Hospital, Lørenskog, ${ }^{2}$ Department of Neurology, Akershus University Hospital, Nordbyhagen, ${ }^{3}$ Department of General Practice, Institute of Health and Society, University of Oslo, Oslo, ${ }^{4}$ Institute of Clinical Medicine, Campus Akershus University Hospital, University of Oslo, Nordbyhagen, Norway}

Correspondence: Espen Saxhaug Kristoffersen

Department of General Practice, Institute of Health and Society,

University of Oslo, PO Box II 30

Blindern, 0318 Oslo, Norway

$\mathrm{Tel}+4722850550$

Fax +47 22850650

Email e.s.kristoffersen@medisin.uio.no
Abstract: Medication-overuse headache $(\mathrm{MOH})$ is a worldwide health problem with a prevalence of $1 \%-2 \%$. It is a severe form of headache where the patients often have a long history of headache and of unsuccessful treatments. $\mathrm{MOH}$ is characterized by chronic headache and overuse of different headache medications. Through the years, withdrawal of the overused medication has been recognized as the treatment of choice. However, currently, there is no clear consensus regarding the optimal strategy for management of $\mathrm{MOH}$. Treatment approaches are based on expert opinion rather than scientific evidence. This review focuses on aspects of epidemiology, diagnosis, pathogenesis, prevention, and treatment of $\mathrm{MOH}$. We suggest that information and education about the risk of $\mathrm{MOH}$ is important since the condition is preventable. Most patients experience reduction of headache days and intensity after successful treatment. The first step in the treatment of $\mathrm{MOH}$ should be carried out in primary care and focus primarily on withdrawal, leaving prophylactic medication to those who do not manage primary detoxification. For most patients, a general practitioner can perform the follow-up after detoxification. More complicated cases should be referred to neurologists and headache clinics. Patients suffering with $\mathrm{MOH}$ have much to gain by an earlier treatment-focused approach, since the condition is both preventable and treatable.

Keywords: medication-overuse headache, migraine, chronic headache, dependence

\section{Introduction}

Headache disorders are a major public health concern given their high prevalence and the large amount of associated disability and financial costs to both the individual and society. ${ }^{1-4}$ According to the Global Burden of Disease Study from 2010, headache is among the top ten causes of disability measured as years of life lost to disability (YLDs). ${ }^{4}$

Headache usually occurs episodically, but $2 \%-5 \%$ of the general population have headache on $\geq 15$ days per month, defined as chronic headache. ${ }^{5-9}$ Patients with chronic headache represent a large population in primary care and neurology settings. ${ }^{10-12}$ Headache is usually treated with analgesics, and is probably the most common reason for use of analgesics in the general population. ${ }^{13-17}$ Studies have identified $20 \%-40 \%$ of the general population to use analgesics over the previous 14 days. ${ }^{15,16,18}$ In Denmark, sales figures of over-the-counter (OTC) analgesics were extrapolated to correspond to almost $8 \%$ of the general population taking the highest recommended daily dose every day for a whole year. ${ }^{19}$

Too much use of symptomatic medication for headaches may lead to medicationoveruse headache (MOH). ${ }^{9}$ This is a condition characterized by chronic headache and 
overuse of different acute headache medications. Withdrawal headache after overuse of ergotamine was described in the early $1950 \mathrm{~s}$, and since the $1980 \mathrm{~s}$, studies have shown that frequent intake of symptomatic headache medication may transform episodic headache to chronic headache. ${ }^{20-25}$

The treatment of $\mathrm{MOH}$ is often complex and withdrawal of the overused medication is recognized as the treatment of choice. ${ }^{26}$ Although several reviews on $\mathrm{MOH}$ have already been published, ${ }^{27-31}$ this review attempts to give an update on different aspects of $\mathrm{MOH}$.

\section{Classification of headache disorders and $\mathrm{MOH}$}

Headache is a subjective symptom, and no laboratory tests or other objective tests are available to diagnose headache. Classification and diagnostic criteria are therefore of essential importance both in clinical practice and research settings. Until 1960, headache diagnoses and studies were based on nonuniform descriptions of symptomatology. Diagnostic criteria for headache were first presented in 1962 when an ad hoc committee of the National Institutes of Health published a first set of criteria. ${ }^{32}$ In 1988, the International Headache Society (IHS) published a classification system that became the standard for headache diagnosis: Classification and diagnostic criteria for headache disorders, cranial neuralgias and facial pain. ${ }^{33}$ In the 1988 edition, the diagnosis "headache induced by chronic substance use or exposure" was taken into the classification. In 2004, a second edition "The International Classification of Headache Disorders (ICHD-II)" was published, and the term "medication-overuse headache" was introduced. ${ }^{34}$ To be more applicable to patients in clinical practice, the diagnostic criteria for $\mathrm{MOH}$ were revised twice for the ICHD-II. ${ }^{35-37}$ Before the last revision, $\mathrm{MOH}$ should paradoxically be entitled as "probable $\mathrm{MOH}$ " until overuse was discontinued, and then, if the patient improved after detoxification, given a definite $\mathrm{MOH}$ diagnosis. This meant that the patient could not receive a definite diagnosis of $\mathrm{MOH}$ until after a successful withdrawal of medication, following which she/he would no longer have $\mathrm{MOH}$.

In 2013, a new version, "The International Classification of Headache Disorders 3rd beta edition (ICHD-IIIb)", was published, taking these changes to $\mathrm{MOH}$ into account. ${ }^{9}$

According to the ICHD-IIIb, "MOH is headache occurring on 15 or more days per month developing as a consequence of regular overuse of acute or symptomatic headache medication (on 10 or more, or 15 or more days per month, depending on the medication) for more than 3 months. It usually, but not invariably, resolves after the overuse is stopped" (Figure 1). With the present criteria, $\mathrm{MOH}$ can be diagnosed immediately, and independently of withdrawal.

$\mathrm{MOH}$ is classified as a secondary chronic headache, but whether $\mathrm{MOH}$ is a primary or secondary headache is still under debate, and the concept of medication-overuse in other secondary headaches is unclear. ${ }^{38,39}$ Further, the concept of chronic migraine with medication-overuse is probably one of the most disputed aspects of the classification. ${ }^{38}$

It is worthwhile noting that the classification does not depend on the number of drug units or dosage, but only count the number of days per month with medication use. Further, the pain characteristics and intensity are not a part of the diagnostic criteria since the location of pain varies in $\mathrm{MOH}$.

\section{Epidemiology}

The prevalence of $\mathrm{MOH}$ in the general population in the western world is $1 \%-2 \% .^{5,6,13,40-44}$ However, a recent review concludes that this varies in different parts of the world depending on the definitions used. The review reported a wide range of prevalence, ie, $0.5 \%-7.2 \%{ }^{45}$ The incidence of

\section{Medication-overuse headache}

A. Headache present on $\geq 15$ days per month

B. Regular overuse for more than 3 months of one or more drugs that can be taken for acute and/or symptomatic treatment of headache

C. Headache has developed or markedly worsened during medication-overuse (For simple analgesics and for combination of acute medications, the intake must be 15 days or more per month; for triptans, ergotamines, opioids, and combination analgesics, 10 days per month is enough for a diagnosis of medication-overuse headache)

Figure I International Classification of Headache Disorders, 3rd beta edition criteria for medication-overuse headache.

Note: Copyright (c) 2013, International Headache Society. Adapted from Headache Classification Committee of the International Headache Society. The International Classification of Headache Disorders. 3rd ed (beta version). Cephalalgia. 2013;33(9):629-808.9 
$\mathrm{MOH}$ was 0.72 per 1,000 person-years in a large prospective cohort study from Norway. ${ }^{46}$

The male to female ratio is $1: 3-4$, and the condition is most prevalent in the forties. ${ }^{40,44}$ The prevalence seems to decrease with increasing age, and among people over 65 years, the prevalence based on different definitions has been reported to be $1.0 \%-1.5 \% .{ }^{47,48}$ The prevalence of $\mathrm{MOH}$ in children and adolescents has been suggested to be $0.3 \%-0.5 \%{ }^{49,50}$ In studies of specialist care in children, approximately $20 \%$ of patients with chronic headache had medication-overuse, suggesting $\mathrm{MOH}$ to be a problem also in school-aged children. ${ }^{51,52}$ It is suggested that $\mathrm{MOH}$ generally starts earlier in life than other types of chronic headache. ${ }^{43}$

\section{Medication use and health care utilization}

While over-the-counter drugs are the most commonly overused headache medications in primary care, accounting for approximately $60 \%$ of overused medication, secondary and tertiary care have a greater proportion of $\mathrm{MOH}$ patients who overuse more potent centrally acting drugs like combination analgesics and opioids. ${ }^{40,41,53-57}$ In addition, many $\mathrm{MOH}$ patients overuse more than one type of acute medication. ${ }^{27,30}$

The drugs implicated in $\mathrm{MOH}$ change over time and differ between regions. ${ }^{53}$ As an example, butalbital-containing medicine is still a problem in the USA, but is banned in the European Union. ${ }^{58}$ Ergotamine is no longer the large problem it once was in western Europe, but still is in other parts of the world. However, triptans are now one of the most common causes of $\mathrm{MOH}$ in the Western world, but are probably too expensive to be a big problem in developing countries, where simple analgesics and ergotamine are much cheaper options.

The clinical features of $\mathrm{MOH}$ caused by different headache medications are quite similar. The fact that many patients overuse more than one type of acute headache drug makes it somewhat difficult to conclude if different types of drugs give different types of headache characteristics. However, one study showed that people overusing triptans developed a more migraine-like headache, in contrast with those overusing ergotamines and analgesics, who developed a more tension-type-like headache. ${ }^{59}$ In another study, $\mathrm{MOH}$ caused by a combination of analgesics and triptans resulted in a higher frequency and intensity of headache, but this needs to be further explored. ${ }^{60}$

In the general population, only $5 \%-15 \%$ of $\mathrm{MOH}$ patients use prophylactic medication, which is a low number considering the chronicity of the headache and frequent medication use. ${ }^{54,55,61}$ The relative frequency of $\mathrm{MOH}$ in secondary and tertiary care is considerably higher than in primary care and in the general population. Headache clinics report that $50 \%-70 \%$ of their patients are overusing medication. $23,57,62-65$

Two studies have investigated health care utilization among $\mathrm{MOH}$ patients in the general population. In a Swedish study, $46 \%$ had made a headache-related visit to their general practitioner and 14\% had visited a neurologist during the previous year. ${ }^{61}$ The corresponding figures of lifetime headacherelated contacts in a study from Norway were approximately $80 \%$ (general practitioner) and 20\% (neurologist). ${ }^{54,55}$ Thus, most $\mathrm{MOH}$ patients have been in contact with their general practitioner, and many have had such contact in the previous year. More surprisingly, 20\% self-managed their headache and had never consulted a physician. ${ }^{54,55}$ As many as three quarters of subjects in the Norwegian study had tried complementary and alternative treatment. ${ }^{54,55}$

\section{Societal consequences of $\mathrm{MOH}$}

$\mathrm{MOH}$ patients experience reduced quality of life compared with those who do not suffer from headaches, but it is unknown if this is related to headache frequency or $\mathrm{MOH}$ per se, as chronic headache sufferers also show the same pattern. ${ }^{43,66,67}$ Disability measured with the Migraine Disability Assessment (MIDAS) questionnaire is high in $\mathrm{MOH} .{ }^{66,68-70}$ In the recent Global Burden of Disease Study, ${ }^{4} \mathrm{MOH}$ was not a part of the final analysis. However, based on the disability weight given $\mathrm{MOH}$ in the study and the high worldwide prevalence, it is speculated that $\mathrm{MOH}$ causes a highly significant number of years of life lost to disability. ${ }^{71}$

In a recent assessment of direct and indirect costs of headache disorders in Europe, indirect loss due to reduced productivity and absenteeism accounted for about $90 \%$ of costs. ${ }^{2}$ The individual costs of $\mathrm{MOH}$ were higher than those for migraine, and the total national costs for headache disorders in some countries were estimated to be higher for $\mathrm{MOH}$ than for migraine. Thus, $\mathrm{MOH}$ is probably the most costly headache disorder for both society and the sufferer, and the worldwide personal and economic costs are enormous.

\section{Risk factors for MOH}

It is well known that previous primary headaches such as migraine and tension-type headache are the most important risk factors for the development of $\mathrm{MOH} .{ }^{43,64,72}$ The proportion of patients with migraine or tension-type headache as their primary headache disorder differ depending on the classification used 
and at which health care level the investigation was conducted; $50 \%-70 \%$ have co-occurrence of migraine in populationbased studies compared with $80 \%-100 \%$ for co-occurrence of migraine in studies from some headache centers. $5,6,26,40,65,73$

Many psychosocial and socioeconomic factors are associated with $\mathrm{MOH}$. However, whether these are directly or indirectly associated is hard to ascertain because the findings are mainly based on cross-sectional studies. In addition, many of these factors may merely be markers of a complex health situation since many aspects may be affected by having chronic headache, as with other chronic conditions.

As for other frequent headaches, $\mathrm{MOH}$ patients tend to be of low socioeconomic status with low income and education, but it is uncertain whether this may be a cause of or an effect of headache..$^{40,42,61,74,75}$ A high prevalence of smoking, elevated body mass index, and sleeping problems have also been found among $\mathrm{MOH}$ patients. ${ }^{42,44}$ Depression and anxiety was more common in $\mathrm{MOH}$ patients than in people with episodic migraine, but in another study this was related to the headache frequency rather than headache diagnosis, so the cause-effect relationship is still unclear. ${ }^{70,76,77}$ An association has also been shown for $\mathrm{MOH}$ and subclinical obsessivecompulsive disorders and mood disorders. ${ }^{78}$

In one study, the risk of developing $\mathrm{MOH}$ was greater in individuals with a family history of $\mathrm{MOH}$ or other substance abuse, suggesting a possible hereditary susceptibility. ${ }^{79}$ However, it is not possible based on that study to conclude whether this was due to genetic or environmental factors, or both.

Data from a population-based longitudinal study suggested that those who used analgesics daily or weekly at baseline compared with those without such medication use had a higher risk of developing chronic headache when followed up 11 years later. ${ }^{14} \mathrm{~A}$ more recent study identified several risk factors for $\mathrm{MOH}$ among people with chronic headache (11 years follow-up). ${ }^{46}$ Regular use of tranquilizers, a combination of chronic musculoskeletal disorders and gastrointestinal complaints, and increased Hospital Anxiety and Depression Scale score, as well as smoking and physical inactivity, increased the risk for $\mathrm{MOH}$. The referred study is extensive and includes over 25,000 people at risk for chronic headache and $\mathrm{MOH} .{ }^{46}$ However, risk factors were only found in a minority of all $\mathrm{MOH}$ patients, and may reflect the complex situation for specific groups of $\mathrm{MOH}$ patients. ${ }^{46}$

\section{Pathogenesis}

Approximately half of those who experience headache on $\geq 15$ days per month have $\mathrm{MOH} .{ }^{5,6}$ Most headache experts regard the association between overuse of acute medication and development of $\mathrm{MOH}$ as causal. ${ }^{26,80}$ Improvement in two thirds to three quarters of patients after successful medication withdrawal supports its causative role in generating or maintaining chronic headache. However, it is still a matter of debate whether the overuse is a consequence or cause of chronic headache. ${ }^{81,82}$ Further, not all headache patients with medication-overuse develop $\mathrm{MOH}$, and the mechanism behind how chronic exposure to abortive medication leads to $\mathrm{MOH}$ remains unclear.

Virtually all acute headache medication may cause $\mathrm{MOH}$. It has been suggested that the mean critical duration of overuse is shortest for triptans (1.7 years), longer for ergotamine (2.7 years), and longest for simple analgesics ( 4.8 years). The mean critical monthly intake frequency in the same study was lowest for triptans, higher for ergotamine, and highest for analgesics. ${ }^{59}$

A pre-existing headache disorder seems to be required to develop $\mathrm{MOH} .^{72}$ Patients with migraine or tension-type headache have a higher potential for developing $\mathrm{MOH}$ than other primary headaches. ${ }^{43,64}$ However, patients with cluster headaches may also develop $\mathrm{MOH}$, but most of these patients have co-occurrence of migraine or a positive family history of migraine. ${ }^{83} \mathrm{MOH}$ does not develop in persons without a history of headache when medication is taken regularly for other conditions, such as arthritis or inflammatory bowel disease. ${ }^{72,84}$ Thus, a connection between headache-specific pain pathways and the effects of headache medication seems to be a central factor in generating a more chronic pain. However, since the different primary headaches have different underlying pathophysiology, and the different medications have different pharmacological actions, it is unlikely that $\mathrm{MOH}$ is caused by the specific action of any single agent. Mechanisms may differ from one class of overused drug to another, and different possible pathogenetic mechanisms have been suggested. It is of course possible that there is a common as yet unknown mechanism by which pharmacologically different medications lead to $\mathrm{MOH}$ independently of underlying primary headache. However, at present, it is possible only to describe mechanisms (mostly from preclinical studies) that appear to be associated with or may predispose people to develop $\mathrm{MOH}$.

A hereditary susceptibility to $\mathrm{MOH}$ has been suggested, as the risk of developing $\mathrm{MOH}$ is greater in individuals with a family history of $\mathrm{MOH}$ or other substance abuse. ${ }^{79}$ A few studies have identified molecular genetic factors that are possibly associated with both $\mathrm{MOH}$ and the response to treatment after withdrawal; however, these results are from small studies in selected groups and the generalizability of 
the findings is difficult to ascertain. ${ }^{85-88}$ Thus, further studies are required.

Alteration of cortical neuronal excitability, central sensitization involving the trigeminal nociceptive system, and changes in serotonergic and dopaminergic expression and pathways including the endocannabinoid system have been suggested to play a part in the pathophysiology of $\mathrm{MOH} .{ }^{85,86,89-92}$

Low serotonin (5-HT) levels with reduction of 5-HT in platelets and up-regulation of a pro-nociceptive $5-\mathrm{HT}_{2 \mathrm{~A}}$ receptor have been demonstrated in $\mathrm{MOH} .{ }^{93,94} \mathrm{~A}$ higher frequency of CSD has been found in animals with low 5-HT levels, suggesting an association with sensitization processes. ${ }^{95,96}$ Further, chronic, but not acute, administration of paracetamol led to an increase in the frequency of cortical spreading depression in another rat model, which may indicate that chronic analgesic exposure leads to hyperexcitability in cortical neurons and an increase in cortical spreading depression. ${ }^{97}$ A $5-\mathrm{HT}_{2 \mathrm{~A}}$ receptor antagonist blocked this increased cortical spreading depression susceptibility in rats that had been exposed to chronic paracetamol. ${ }^{98}$

Chronic use of opioids and triptans has been shown to increase calcitonin gene-related peptide (CGRP) levels, which are involved in neurogenic inflammation and headache pain..$^{90,99}$

In addition, chronic morphine infusion may alter diffuse noxious inhibitory controls, and impaired diffuse noxious inhibitory controls are also found in $\mathrm{MOH} .{ }^{100}$

Another important phenomenon related to $\mathrm{MOH}$ is central sensitization, which has for a long time been suggested to play an important role and has recently been described clinically in $\mathrm{MOH}$ patients with normalization after withdrawal of the overused medication. ${ }^{101,102}$

The endocannabinoid system is involved in modulating pain and plays a role in the common neurobiological system underlying drug addiction and reward. ${ }^{103}$ Both an endocannabinoid membrane transporter and levels of endocannabinoids in platelets were reduced in $\mathrm{MOH}$ and chronic migraine patients compared with controls. ${ }^{103,104}$

In $\mathrm{MOH}$ patients, increased levels of orexin-A and corticotrophin-releasing hormone were found in the cerebrospinal fluid compared with levels in patients with chronic migraine, and were correlated with monthly drug intake. ${ }^{105}$

In addition, neuroimaging studies suggest changes in the orbitofrontal cortex and the mesocorticolimbic dopamine circuit. $^{106-109}$

In conclusion, the complex pathophysiology behind $\mathrm{MOH}$ is still only partly known. However, it is clear that many of these phenomena are similar to, and thus may involve, mechanisms seen in dependence processes, ${ }^{89,110}$ and it is equally clear that more research is needed in all these areas.

\section{Medication dependence in $\mathrm{MOH}$ ?}

Whether $\mathrm{MOH}$ is a kind of dependence or just dependencylike behavior is still a matter of debate. Some authors have advocated the division of $\mathrm{MOH}$ into two subgroups depending on the type of overused medication and comorbidity. ${ }^{111,112}$

Codeine and opioids are not recommended in the treatment of tension-type headache or migraine. Regardless of this, it is well known that many $\mathrm{MOH}$ patients use these agents. ${ }^{113,114}$ Further, many countries have codeine (which is metabolized to opioids) and caffeine-containing analgesics available as over-the-counter drugs. Codeine, opioids, and caffeine are known to be psychotropic drugs, so abuse and dependence may be a problem with some headache drugs. ${ }^{115-117}$

Theoretical considerations also show many similarities between $\mathrm{MOH}$ and drug addiction. ${ }^{110}$ In addition, recent studies in neuroimaging suggest an overlap of the pathophysiological mechanisms of $\mathrm{MOH}$ and substance-related disorders with changes in the orbitofrontal cortex and the mesocorticolimbic dopamine circuit. ${ }^{106-109}$

Although triptans and simple analgesics are not regarded as psychotropic agents, patients with $\mathrm{MOH}$ seem to share some characteristics with dependence. Previous studies from Norway have revealed that $\mathrm{MOH}$ can be easily detected in a population using a screening instrument for behavioral dependence, ie, the Severity of Dependence Scale (SDS). ${ }^{11-120}$ The SDS has high sensitivity, specificity, and positive and negative predictive values for detecting chronic headache patients with $\mathrm{MOH} .{ }^{119-121}$ In addition, the SDS score has been shown to predict the likelihood of successful detoxification in a general population. ${ }^{122}$ However, the SDS has not been validated against other measurements of dependency in $\mathrm{MOH}$ sufferers.

In two studies, approximately $70 \%$ of $\mathrm{MOH}$ patients fulfilled criteria for dependence according to the DSM-IV (Diagnostic and Statistical Manual of Mental Disorders, Fourth Edition). ${ }^{123,124}$ However, use of DSM-IV criteria in patients with $\mathrm{MOH}$ has been criticized since it may overestimate dependence. ${ }^{125}$ In other studies, the dependence and personality profile score in the Minnesota Multiphasic Personality Inventory II (MMPI-II) did not reveal any differences between $\mathrm{MOH}$ patients, drug addicts, and controls. $^{126,127}$

Another study found that the dependency score based on the Leeds Dependency Questionnaire was similarly increased 
in $\mathrm{MOH}$ patients and illegal drug addicts. ${ }^{128}$ However, in contrast with drug addicts, it was not the type of drug that was most important for the $\mathrm{MOH}$ patients, but the effect of the drug. ${ }^{128}$ However, the high relapse into medication-overuse, even after successful withdrawal and improvement of the headache situation, has been suggested to be some kind of "drive" for medication.

A qualitative study suggested that patients with $\mathrm{MOH}$ hold on to what they consider to be "indispensable medication". ${ }^{129}$ The MOH patients were seeking for the pain relief; they did not view themselves as dependent and felt offended by that suggestion. ${ }^{129}$

Based on today's knowledge, it is impossible to ascertain whether the dependency-like behavior seen in those with $\mathrm{MOH}$ represents a real dependence or whether it is a form of "pseudoaddiction" secondary to frequent headache. ${ }^{111,112,130-132}$

\section{Treatment}

$\mathrm{MOH}$ is a treatable but very heterogeneous condition. ${ }^{112,130,133}$ A further challenge in the treatment is the fact that no worldwide consensus for the management of these patients exists. This may be due to the lack of randomized controlled studies, but also reflects differences in use of headache classification and treatment strategies across the world.

Whether or not to detoxify $\mathrm{MOH}$ patients initially and whether prophylactic medication should be initiated immediately at withdrawal or after withdrawal therapy has been completed are probably the most disputed areas in the treatment of $\mathrm{MOH} .{ }^{26,134-136}$ Although recently debated, withdrawal of the overused medication(s) is regarded by most headache experts as the treatment of choice, since withdrawal of the overused medication(s) in most cases leads to an improve-

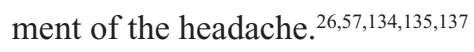

Most patients experience withdrawal symptoms lasting 2-10 days after detoxification. The most common symptom is an initial worsening of the headache (rebound-headache), accompanied by various degrees of nausea, vomiting, hypotension, tachycardia, sleep disturbances, restlessness, anxiety, and nervousness. The duration of withdrawal headaches has been found to vary with different drugs, being shorter in patients overusing triptans than in those overusing ergotamine or analgesics. ${ }^{138}$

Detoxification procedures vary widely and include both inpatient ( 2 days to 2 weeks) and outpatient withdrawal. ${ }^{73,133,139-142}$ The different strategies include abrupt or tapered withdrawal with just simple advice, multidisciplinary approaches, use of antiemetics, neuroleptics, rescue medication (an analgesic other than the overused one), and intravenous hydration. Steroids have for a long time been expected to alleviate withdrawal headache in the acute phase, but two placebo-controlled studies did not find prednisolone (60 mg or $100 \mathrm{mg}$ for 5 days) superior to placebo. ${ }^{143,144}$ However, it is still debated if it may be useful in certain subgroups of patients.

Independent of the strategy used, the main aims of treatment are withdrawal of the overused medication and continuing support (pharmacological and nonpharmacological) to prevent relapse. Comorbidity with other medical conditions (including psychiatric disorders) has to be treated in addition to withdrawal therapy to avoid relapse.

Headache centers often report treatment success rates of around $70 \%$. These results are commonly based on inpatient treatment, rescue medication, and continued support. However, the definition of success rate is based on very variable outcome measures and therefore difficult to compare. ${ }^{145}$

Some studies have supported the effect of simple advice for $\mathrm{MOH}$ in the general population and in a headache clinic. ${ }^{133,146-148}$ In a previous population-based study from Norway, simple information on medication use led to improvement, with $42 \%$ of patients reverting to episodic headache and $76 \%$ being free of medication-overuse after 1.5 years. The study was observational and lacked a control group, but the effect of simple information was supported by the fact that the participants had had $\mathrm{MOH}$ for 8-18 years prior to the interview during which the information was given. ${ }^{146}$ Two Italian studies in neurology settings reported that $78 \%-92 \%$ of patients with simple $\mathrm{MOH}$ and $60 \%$ of those with complicated $\mathrm{MOH}$ became free of chronic headache and medication-overuse 2 months after receiving simple advice. ${ }^{133,147,148}$ Even previously treatment-resistant $\mathrm{MOH}$ patients from a tertiary headache center experienced lasting improvement after withdrawal of medication. ${ }^{69}$ Based on our clinical experience, most patients overusing simple analgesics as well as codeinecontaining combination analgesics and triptans manage abrupt withdrawal without tapering. Patients overusing heavier drugs with physical abstinence profiles may be a different matter and these patients may need other withdrawal strategies.

However, in most countries in Europe, simple analgesics, triptans, and combination analgesics clearly dominate. . $^{40,43,55}$ Because there seems to be no difference between inpatient and outpatient withdrawal, the less resource-demanding outpatient withdrawal is in our opinion the preferred method. ${ }^{133,139,141,149}$ 
Placebo-controlled studies of various prophylactic medications (adding prophylactic medication without initial withdrawal) in the treatment of $\mathrm{MOH}$ have found a significant reduction in migraine and headache days per month compared with placebo. ${ }^{136,150-154}$ However, there are methodological concerns with these studies when addressing $\mathrm{MOH}$, in particular based on the inclusion of a mixed population of chronic migraine with and without medication-overuse. However, these results do not seem to be superior to initial detoxification without prophylactic medication in other studies. ${ }^{73,133,135}$ Recent studies from headache centers have also used the combination of initial withdrawal and prophylactic medication with some superiority when compared with only initial withdrawal in the short-term; however, in the long-term results, there are no differences between the groups with or without prophylactic medication. ${ }^{69,73,155}$

Therefore, based on today's knowledge, we suggest that initial withdrawal is the treatment of choice. Prophylactic headache medication should be restricted to patients who do not benefit sufficiently from cessation of medication-overuse, and those who have previously failed withdrawal attempts or have significant comorbidity. Some authors contest this view since many $\mathrm{MOH}$ patients are already suffering and heavily disabled before starting a possible troublesome detoxification with withdrawal symptoms. However, it is an aim in itself to achieve a behavioral change and to restructure the approach from "have pain - take tablet" thinking to better ways of handling headache. In addition, a period free of medicationoveruse has been suggested to lead to recovery of prophylactic responsiveness. ${ }^{156}$ For patients still needing prophylactic medication after withdrawal, the choice should be based on the underlying primary headache, comorbidity, and possible side effects of treatment. Other more experimental treatments, such as surgery and neuromodulation, have conflicting results and should not be recommended before new evidence clearly demonstrates a clinical effect. ${ }^{157,158}$

\section{Long-term outcome and relapse rate}

Most follow-up studies are conducted in tertiary care centers and may reflect selected populations. However, one study supports that patients initially detoxified as inpatients can be followed up by their general practitioner. ${ }^{159}$

Studies have reported a $20 \%-40 \%$ relapse rate within the first year after withdrawal. Only few relapse after 12 months. ${ }^{159-166}$ There are conflicting results regarding at what time during the first year patients relapse, with some suggesting that most patients relapse within the first 6 months and others suggesting between 6 and 12 months. ${ }^{160-162,166,167}$ The literature is not clear regarding to what degree the pre-existent headache type or type of overused medication predicts successful withdrawal or relapse..$^{59,159-166}$ In addition, the results on relapse should be compared with some caution, since the studies varied in their use of headache classification systems, withdrawal, and prophylaxis, as well as in duration of follow-up and the criteria used to detect improvement.

\section{Prevention}

A small study from England reported that both people with headache and those without headache were unaware of the risk of $\mathrm{MOH}$ resulting from frequent analgesic use for headache. ${ }^{168}$ Other studies have found that most $\mathrm{MOH}$ patients do not know about the relationship between medication-overuse and headache chronification. ${ }^{61,62,147}$ The authors suggest it is possible that the patients had been informed but did not remember or had not fully understood the information. In a German study, a brochure on medication-overuse helped to prevent development of $\mathrm{MOH}$ in people with migraine and frequent medication use. ${ }^{169}$

Considering that possibly anyone with primary episodic headache may be at risk of developing $\mathrm{MOH}$, the number of people at risk is high. Adding the fact that, in many cases, just simple advice leads to successful medication withdrawal, the potential benefit of giving information on $\mathrm{MOH}$ is high. New information campaigns and strategies to target people at risk have to be developed.

Given that most patients with $\mathrm{MOH}$ have been in contact with a general practitioner, and almost half have had such contact in the previous year, primary care is probably the ideal setting for prevention and treatment of headache and medication-overuse. ${ }^{54,55,61}$ The general practitioner has a key role in providing patient education and prophylactic headache medication before headaches become chronic. Further, general practitioners have the continued and clear responsibility for the patients over time. This long-term alliance with their own patients may further enhance the treatment effects and avoidance of relapse. Taking care of uncomplicated cases in primary care may also free up more resources for referrals to neurologists of complicated cases.

\section{Conclusion}

$\mathrm{MOH}$ is a treatable and preventable public health problem worldwide. The improvements seen in two of three $\mathrm{MOH}$ patients after withdrawal suggest that detoxification is the logical first step in treatment. Prevention as well as treatment should probably be attempted in primary care, leaving 
the more complicated cases to neurologists. The gain from treating patients with $\mathrm{MOH}$ is potentially high, and may lead to substantial economic savings for society as well as for individual patients.

\section{Acknowledgment}

The authors received research funding for this work from the Research Centre at Akershus University Hospital, and the University of Oslo.

\section{Disclosure}

The authors declare that they have no competing interests in this work.

\section{References}

1. Jensen R, Stovner LJ. Epidemiology and comorbidity of headache. Lancet Neurol. 2008;7(4):354-361.

2. Linde M, Gustavsson A, Stovner LJ, et al. The cost of headache disorders in Europe: the Eurolight project. Eur J Neurol. 2012;19(5):703-711.

3. Stovner L, Hagen K, Jensen R, et al. The global burden of headache: a documentation of headache prevalence and disability worldwide. Cephalalgia. 2007;27(3):193-210.

4. Vos T, Flaxman AD, Naghavi M, et al. Years lived with disability (YLDs) for 1160 sequelae of 289 diseases and injuries 1990-2010: a systematic analysis for the Global Burden of Disease Study 2010. Lancet. 2012;380(9859):2163-2196.

5. Aaseth K, Grande RB, Kvaerner KJ, Gulbrandsen P, Lundqvist C, Russell MB. Prevalence of secondary chronic headaches in a populationbased sample of 30-44-year-old persons. The Akershus study of chronic headache. Cephalalgia. 2008;28(7):705-713.

6. Grande RB, Aaseth K, Gulbrandsen P, Lundqvist C, Russell MB. Prevalence of primary chronic headache in a population-based sample of 30- to 44-year-old persons. The Akershus study of chronic headache. Neuroepidemiology. 2008;30(2):76-83.

7. Lantéri-Minet M, Auray JP, El Hasnaoui A, et al. Prevalence and description of chronic daily headache in the general population in France. Pain. 2003;102(1-2):143-149.

8. Castillo J, Munoz P, Guitera V, Pascual J. Kaplan Award 1998. Epidemiology of chronic daily headache in the general population. Headache. 1998;39(3):190-196.

9. Headache Classification Committee of the International Headache Society. The International Classification of Headache Disorders. 3rd ed (beta version). Cephalalgia. 2013;33(9):629-808.

10. Latinovic R, Gulliford M, Ridsdale L. Headache and migraine in primary care: consultation, prescription, and referral rates in a large population. J Neurol Neurosurg Psychiatry. 2006;77(3):385-387.

11. Ridsdale L, Clark LV, Dowson AJ, et al. How do patients referred to neurologists for headache differ from those managed in primary care? Br J Gen Pract. 2007;57(538):388-395.

12. Patterson VH, Esmonde TF. Comparison of the handling of neurological outpatient referrals by general physicians and a neurologist. J Neurol Neurosurg Psychiatry. 1993;56(7):830.

13. Zwart JA, Dyb G, Hagen K, Svebak S, Stovner LJ, Holmen J. Analgesic overuse among subjects with headache, neck, and low-back pain. Neurology. 2004;62(9):1540-1544.

14. Zwart JA, Dyb G, Hagen K, et al. Analgesic use: a predictor of chronic pain and medication overuse headache. Neurology. 2003;61(2): $160-164$.

15. Eggen AE. The Tromso Study: frequency and predicting factors of analgesic drug use in a free-living population (12-56 years). J Clin Epidemiol. 1993;46(11):1297-1304.
16. Antonov KI, Isacson DG. Prescription and nonprescription analgesic use in Sweden. Ann Pharmacother. 1998;32(4):485-494.

17. Mehuys E, Paemeleire K, Van Hees T, et al. Self-medication of regular headache: a community pharmacy-based survey. Eur J Neurol. 2012;19(8):1093-1099.

18. Porteous T, Bond C, Hannaford P, Sinclair H. How and why are non-prescription analgesics used in Scotland? Fam Pract. 2005;22(1): 78-85.

19. Hargreave M, Andersen TV, Nielsen A, Munk C, Liaw KL, Kjaer SK. Factors associated with continuous regular analgesic use - a populationbased study of more than 45,000 Danish women and men 18-45 years of age. Pharmacoepidemiol Drug Saf. 2010;19(1):65-74.

20. Horton BT, Peters GA. Clinical manifestations of excessive use of ergotamine preparations and mangement of withdrawal effect: report of 52 cases. Headache. 1963;2:214-227.

21. Peters GA, Horton BT. Headache: with special reference to the excessive use of ergotamine preparations and withdrawal effects. Proc Staff Meet Mayo Clin. 1951;26(9):153-161.

22. Peters GA, Horton BT. Headache; with special reference to the excessive use of ergotamine tartrate and dihydroergotamine. J Lab Clin Med. 1950;36(6):972-973.

23. Mathew NT, Kurman R, Perez F. Drug induced refractory headacheclinical features and management. Headache. 1990;30(10):634-638.

24. Diener HC, Dichgans J, Scholz E, Geiselhart S, Gerber WD, Bille A. Analgesic-induced chronic headache: long-term results of withdrawal therapy. J Neurol. 1989;236(1):9-14.

25. Kudrow L. Paradoxical effects of frequent analgesic use. Adv Neurol. 1982;33:335-341.

26. Evers S, Jensen R; European Federation of Neurological Societies. Treatment of medication overuse headache - guideline of the EFNS headache panel. Eur J Neurol. 2011;18(9):1115-1121.

27. Diener HC, Limmroth V. Medication-overuse headache: a worldwide problem. Lancet Neurol. 2004;3(8):475-483.

28. Katsarava Z, Jensen R. Medication-overuse headache: where are we now? Curr Opin Neurol. 2007;20(3):326-330.

29. Rossi P, Jensen R, Nappi G, Allena M; COMOESTAS Consortium. A narrative review on the management of medication overuse headache: the steep road from experience to evidence. J Headache Pain. 2009;10(6):407-417.

30. Evers S, Marziniak M. Clinical features, pathophysiology, and treatment of medication-overuse headache. Lancet Neurol. 2010;9(4):391-401.

31. Kristoffersen ES, Lundqvist C. Medication-overuse headache: epidemiology, diagnosis and treatment. Ther Adv Drug Saf. 2014;5(2): 87-99.

32. Ad Hoc Committee on Classification of Headache of the National Institute of Health. Classification of headache. JAMA. 1962;179:717-718.

33. Headache Classification Committee of the International Headache Society. Classification and diagnostic criteria for headache disorders, cranial neuralgias and facial pain. Cephalalgia. 1988;8 Suppl 7:1-96.

34. Headache Classification Committee of the International Headache Society. The International Classification of Headache Disorders: 2nd ed. Cephalalgia. 2004;24 Suppl 1:9-160.

35. Cephalalgia. Erratum. Cephalalgia. 2006;26(3):360.

36. Olesen J, Bousser MG, Diener HC, et al. New appendix criteria open for a broader concept of chronic migraine. Cephalalgia. 2006;26(6): $742-746$.

37. Silberstein SD, Olesen J, Bousser MG, et al. The International Classification of Headache Disorders, 2nd ed (ICHD-II) - revision of criteria for 8.2 Medication-overuse headache. Cephalalgia. 2005;25(6): 460-465.

38. Sun-Edelstein C, Bigal ME, Rapoport AM. Chronic migraine and medication overuse headache: clarifying the current International Headache Society classification criteria. Cephalalgia. 2009;29(4): 445-452.

39. Grazzi L, Bussone G. Medication overuse headache (MOH): complication of migraine or secondary headache? Neurol Sci. 2012; 33 Suppl 1:S27-S28. 
40. Jonsson P, Hedenrud T, Linde M. Epidemiology of medication overuse headache in the general Swedish population. Cephalalgia. 2011;31(9):1015-1022.

41. Lu SR, Fuh JL, Chen WT, Juang KD, Wang SJ. Chronic daily headache in Taipei, Taiwan: prevalence, follow-up and outcome predictors. Cephalalgia. 2001;21(10):980-986.

42. Wiendels NJ, Knuistingh Neven A, Rosendaal FR, et al. Chronic frequent headache in the general population: prevalence and associated factors. Cephalalgia. 2006;26(12):1434-1442.

43. Colás R, Muñoz P, Temprano R, Gómez C, Pascual J. Chronic daily headache with analgesic overuse: epidemiology and impact on quality of life. Neurology. 2004;62(8):1338-1342.

44. Straube A, Pfaffenrath V, Ladwig KH, et al. Prevalence of chronic migraine and medication overuse headache in Germany - the German DMKG Headache Study. Cephalalgia. 2010;30(2):207-213.

45. Westergaard ML, Hansen EH, Glumer C, Olesen J, Jensen RH. Definitions of medication-overuse headache in population-based studies and their implications on prevalence estimates: a systematic review. Cephalalgia. 2014;34(6):409-425.

46. Hagen K, Linde M, Steiner TJ, Stovner LJ, Zwart JA. Risk factors for medication-overuse headache: an 11-year follow-up study. The NordTrøndelag Health Studies. Pain. 2012;153(1):56-61.

47. Wang SJ, Fuh JL, Lu SR, et al. Chronic daily headache in Chinese elderly: prevalence, risk factors, and biannual follow-up. Neurology. 2000;54(2):314-319.

48. Prencipe M, Casini AR, Ferretti C, et al. Prevalence of headache in an elderly population: attack frequency, disability, and use of medication J Neurol Neurosurg Psychiatry. 2001;70(3):377-381.

49. Wang SJ, Fuh JL, Lu SR, Juang KD. Chronic daily headache in adolescents: prevalence, impact, and medication overuse. Neurology. 2006;66(2):193-197.

50. Dyb G, Holmen TL, Zwart JA. Analgesic overuse among adolescents with headache: the Head-HUNT-Youth Study. Neurology. 2006;66(2):198-210.

51. Piazza F, Chiappedi M, Maffioletti E, Galli F, Balottin U. Medication overuse headache in school-aged children: more common than expected? Headache. 2012;52(10):1506-1510.

52. Wiendels NJ, van der Geest MC, Neven AK, Ferrari MD, Laan LA Chronic daily headache in children and adolescents. Headache. 2005;45(6):678-683.

53. Meskunas CA, Tepper SJ, Rapoport AM, Sheftell FD, Bigal ME. Medications associated with probable medication overuse headache reported in a tertiary care headache center over a 15-year period. Headache. 2006;46(5):766-772.

54. Kristoffersen ES, Grande RB, Aaseth K, Lundqvist C, Russell MB Management of primary chronic headache in the general population the Akershus study of chronic headache. J Headache Pain. 2012;13(2):113-120.

55. Kristoffersen ES, Lundqvist C, Aaseth K, Grande RB, Russell MB. Management of secondary chronic headache in the general population: the Akershus study of chronic headache. J Headache Pain. 2013;14(1):5.

56. Scher AI, Lipton RB, Stewart WF, Bigal M. Patterns of medication use by chronic and episodic headache sufferers in the general population: results from the frequent headache epidemiology study. Cephalalgia. 2010;30(3):321-328.

57. Zeeberg P, Olesen J, Jensen R. Probable medication-overuse headache: the effect of a 2-month drug-free period. Neurology. 2006;66(12):1894-1898

58. Tfelt-Hansen PC, Diener HC. Why should American headache and migraine patients still be treated with butalbital-containing medicine? Headache. 2012;52(4):672-674.

59. Limmroth V, Katsarava Z, Fritsche G, Przywara S, Diener HC. Features of medication overuse headache following overuse of different acute headache drugs. Neurology. 2002;59(7):1011-1014.

60. Creac'h C, Radat F, Mick G, et al. One or several types of triptan overuse headaches? Headache. 2009;49(4):519-528.
61. Jonsson P, Linde M, Hensing G, Hedenrud T. Sociodemographic differences in medication use, health-care contacts and sickness absence among individuals with medication-overuse headache. $J$ Headache Pain. 2012;13(4):281-290.

62. Bekkelund SI, Salvesen R. Drug-associated headache is unrecognized in patients treated at a neurological centre. Acta Neurol Scand. 2002;105(2):120-123.

63. Dowson AJ. Analysis of the patients attending a specialist UK headache clinic over a 3-year period. Headache. 2003;43(1):14-18.

64. Bigal ME, Lipton RB. Excessive acute migraine medication use and migraine progression. Neurology. 2008;71(22):1821-1828.

65. Bigal ME, Rapoport AM, Sheftell FD, Tepper SJ, Lipton RB. Transformed migraine and medication overuse in a tertiary headache centre - clinical characteristics and treatment outcomes. Cephalalgia. 2004;24(6):483-490.

66. Lanteri-Minet M, Duru G, Mudge M, Cottrell S. Quality of life impairment, disability and economic burden associated with chronic daily headache, focusing on chronic migraine with or without medication overuse: a systematic review. Cephalalgia. 2011;31(7):837-850.

67. Wiendels NJ, van Haestregt A, Knuistingh Neven A, et al. Chronic frequent headache in the general population: comorbidity and quality of life. Cephalalgia. 2006;26(12):1443-1450.

68. Bendtsen L, Munksgaard S, Tassorelli C, et al. Disability, anxiety and depression associated with medication-overuse headache can be considerably reduced by detoxification and prophylactic treatment. Results from a multicentre, multinational study (COMOESTAS project). Cephalalgia. 2014;34(6):426-433.

69. Munksgaard SB, Bendtsen L, Jensen RH. Treatment-resistant medication overuse headache can be cured. Headache. 2012;52(7): 1120-1129.

70. Wallasch TM, Kropp P. Multidisciplinary integrated headache care: a prospective 12-month follow-up observational study. $J$ Headache Pain. 2012;13(7):521-529.

71. Steiner T. Can we know the prevalence of MOH? Cephalalgia. 2014;34(6):403-404.

72. Bahra A, Walsh M, Menon S, Goadsby PJ. Does chronic daily headache arise de novo in association with regular use of analgesics? Headache. 2003;43(3):179-190.

73. Munksgaard SB, Bendtsen L, Jensen RH. Detoxification of medicationoveruse headache by a multidisciplinary treatment programme is highly effective: a comparison of two consecutive treatment methods in an open-label design. Cephalalgia. 2012;32(11):834-844.

74. Hagen K, Vatten L, Stovner LJ, Zwart JA, Krokstad S, Bovim G. Low socio-economic status is associated with increased risk of frequent headache: a prospective study of 22718 adults in Norway. Cephalalgia. 2002;22(8):672-679.

75. Atasoy HT, Unal AE, Atasoy N, Emre U, Sumer M. Low income and education levels may cause medication overuse and chronicity in migraine patients. Headache. 2005;45(1):25-31.

76. Radat F, Creac'h C, Swendsen JD, et al. Psychiatric comorbidity in the evolution from migraine to medication overuse headache. Cephalalgia. 2005;25(7):519-522.

77. Zwart JA, Dyb G, Hagen K, et al. Depression and anxiety disorders associated with headache frequency. The Nord-Trondelag Health Study. Eur J Neurol. 2003;10(2):147-152.

78. Cupini LM, De MM, Costa C, et al. Obsessive-compulsive disorder and migraine with medication-overuse headache. Headache. 2009;49(7):1005-1013.

79. Cevoli S, Sancisi E, Grimaldi D, et al. Family history for chronic headache and drug overuse as a risk factor for headache chronification. Headache. 2009;49(3):412-418.

80. Bigal ME, Lipton RB. Overuse of acute migraine medications and migraine chronification. Curr Pain Headache Rep. 2009;13(4): 301-307.

81. Dodick DW. Debate: analgesic overuse is a cause, not consequence, of chronic daily headache. Analgesic overuse is not a cause of chronic daily headache. Headache. 2002;42(6):547-554. 
82. Tepper SJ. Debate: analgesic overuse is a cause, not consequence, of chronic daily headache. Analgesic overuse is a cause of chronic daily headache. Headache. 2002;42(6):543-547.

83. Paemeleire K, Bahra A, Evers S, Matharu MS, Goadsby PJ. Medication-overuse headache in patients with cluster headache. Neurology. 2006;67(1):109-113.

84. Wilkinson SM, Becker WJ, Heine JA. Opiate use to control bowel motility may induce chronic daily headache in patients with migraine. Headache. 2001;41(3):303-309.

85. Cevoli S, Mochi M, Scapoli C, et al. A genetic association study of dopamine metabolism-related genes and chronic headache with drug abuse. Eur J Neurol. 2006;13(9):1009-1013.

86. Di Lorenzo C, Di Lorenzo G, Sances G, et al. Drug consumption in medication overuse headache is influenced by brain-derived neurotrophic factor Val66Met polymorphism. J Headache Pain. 2009;10(5):349-355.

87. Di Lorenzo C, Sances G, Di Lorenzo G, et al. The wolframin His611Arg polymorphism influences medication overuse headache. Neurosci Lett. 2007;424(3):179-184.

88. Cargnin S, Viana M, Ghiotto N, et al. Functional polymorphisms in COMT and SLC6A4 genes influence the prognosis of patients with medication overuse headache after withdrawal therapy. Eur J Neurol. Epub 2014 March 29.

89. Cupini LM, Sarchielli P, Calabresi P. Medication overuse headache: neurobiological, behavioural and therapeutic aspects. Pain. 2010;150(2):222-224.

90. De Felice M, Ossipov MH, Wang R, et al. Triptan-induced latent sensitization: a possible basis for medication overuse headache. Ann Neurol. 2010;67(3):325-337.

91. Meng ID, Dodick D, Ossipov MH, Porreca F. Pathophysiology of medication overuse headache: insights and hypotheses from preclinical studies. Cephalalgia. 2011;31(7):851-860.

92. Bongsebandhu-phubhakdi S, Srikiatkhachorn A. Pathophysiology of medication-overuse headache: implications from animal studies. Curr Pain Headache Rep. 2012;16(1):110-115.

93. Srikiatkhachorn A, Anthony M. Serotonin receptor adaptation in patients with analgesic-induced headache. Cephalalgia. 2006;16(6):419-422.

94. Srikiatkhachorn A, Maneesri S, Govitrapong P, Kasantikul V. Derangement of serotonin system in migrainous patients with analgesic abuse headache: clues from platelets. Headache. 1998;38(1):43-49.

95. Supornsilpchai W, Sanguanrangsirikul S, Maneesri S, Srikiatkhachorn A. Serotonin depletion, cortical spreading depression, and trigeminal nociception. Headache. 2006;46(1):34-39.

96. le Grand SM, Supornsilpchai W, Saengjaroentham C, Srikiatkhachorn A. Serotonin depletion leads to cortical hyperexcitability and trigeminal nociceptive facilitation via the nitric oxide pathway. Headache. 2011;51(7):1152-1160.

97. Supornsilpchai W, le Grand SM, Srikiatkhachorn A. Cortical hyperexcitability and mechanism of medication-overuse headache. Cephalalgia. 2010;30(9):1101-1109.

98. Supornsilpchai W, le Grand SM, Srikiatkhachorn A. Involvement of pro-nociceptive 5-HT2A receptor in the pathogenesis of medicationoveruse headache. Headache. 2010;50(2):185-197.

99. Belanger S, Ma W, Chabot JG, Quirion R. Expression of calcitonin gene-related peptide, substance $\mathrm{P}$ and protein kinase $\mathrm{C}$ in cultured dorsal root ganglion neurons following chronic exposure to $\mathrm{mu}$, delta and kappa opiates. Neuroscience. 2002;115(2):441-453.

100. Perrotta A, Serrao M, Sandrini G, et al. Sensitisation of spinal cord pain processing in medication overuse headache involves supraspinal pain control. Cephalalgia. 2010;30(3):272-284.

101. Ayzenberg I, Obermann M, Nyhuis P, et al. Central sensitization of the trigeminal and somatic nociceptive systems in medication overuse headache mainly involves cerebral supraspinal structures. Cephalalgia. 2006;26(9):1106-1114.

102. Munksgaard SB, Bendtsen L, Jensen RH. Modulation of central sensitisation by detoxification in $\mathrm{MOH}$ : Results of a 12-month detoxification study. Cephalalgia. 2013;33(7):444-453.
103. Cupini LM, Costa C, Sarchielli P, et al. Degradation of endocannabinoids in chronic migraine and medication overuse headache. Neurobiol Dis. 2008;30(2):186-189.

104. Rossi C, Pini LA, Cupini ML, Calabresi P, Sarchielli P. Endocannabinoids in platelets of chronic migraine patients and medication-overuse headache patients: relation with serotonin levels. Eur J Clin Pharmacol. 2008;64(1):1-8.

105. Sarchielli P, Rainero I, Coppola F, et al. Involvement of corticotrophinreleasing factor and orexin-A in chronic migraine and medicationoveruse headache: findings from cerebrospinal fluid. Cephalalgia. 2008;28(7):714-722.

106. Chanraud S, Di Scala G, Dilharreguy B, Schoenen J, Allard M, Radat F. Brain functional connectivity and morphology changes in medication-overuse headache: Clue for dependence-related processes? Cephalalgia. Epub 2014 January 21.

107. Ferraro S, Grazzi L, Muffatti R, et al. In medication-overuse headache, fMRI shows long-lasting dysfunction in midbrain areas. Headache. 2012;52(10):1520-1534.

108. Grazzi L, Chiapparini L, Ferraro S, et al. Chronic migraine with medication overuse pre-post withdrawal of symptomatic medication: clinical results and fMRI correlations. Headache. 2010;50(6): 998-1004.

109. Fumal A, Laureys S, Di Clemente L, et al. Orbitofrontal cortex involvement in chronic analgesic-overuse headache evolving from episodic migraine. Brain. 2006;129 Pt 2:543-550.

110. Calabresi P, Cupini LM. Medication-overuse headache: similarities with drug addiction. Trends Pharmacol Sci. 2005;26(2):62-68.

111. Saper JR, Lake AE 3rd. Medication overuse headache: type I and type II. Cephalalgia. 2006;26(10):1262.

112. Lake AE 3rd. Medication overuse headache: biobehavioral issues and solutions. Headache. 2006;46 Suppl 3:S88-S97.

113. Bendtsen L, Evers S, Linde M, et al. EFNS guideline on the treatment of tension-type headache - report of an EFNS task force. Eur J Neurol. 2010;17(11):1318-1325.

114. Evers S, Afra J, Frese A, et al. EFNS guideline on the drug treatment of migraine - revised report of an EFNS task force. Eur J Neurol. 2009;16(9):968-981.

115. Abbott FV, Fraser MI. Use and abuse of over-the-counter analgesic agents. J Psychiatry Neurosci. 1998;23(1):13-34.

116. Cooper RJ. Over-the-counter medicine abuse - a review of the literature. J Subst Use. 2013;18(2):82-107.

117. Cooper RJ. 'I can't be an addict. I am.' Over-the-counter medicine abuse: a qualitative study. BMJ Open. 2013;3(6).

118. Gossop M, Darke S, Griffiths P, et al. The Severity of Dependence Scale (SDS): psychometric properties of the SDS in English and Australian samples of heroin, cocaine and amphetamine users. Addiction. 1995;90(5):607-614.

119. Grande RB, Aaseth K, Saltyte Benth J, Gulbrandsen P, Russell MB, Lundqvist C. The Severity of Dependence Scale detects people with medication overuse: the Akershus study of chronic headache. J Neurol Neurosurg Psychiatry. 2009;80(7): 784-789.

120. Lundqvist C, Aaseth K, Grande RB, Benth JS, Russell MB. The severity of dependence score correlates with medication overuse in persons with secondary chronic headaches. The Akershus study of chronic headache. Pain. 2010;148(3):487-491.

121. Lundqvist C, Benth JS, Grande RB, Aaseth K, Russell MB. An adapted Severity of Dependence Scale is valid for the detection of medication overuse: the Akershus study of chronic headache. Eur J Neurol. 2011;18(3):512-518.

122. Lundqvist C, Grande RB, Aaseth K, Russell MB. Dependence scores predict prognosis of medication overuse headache: a prospective cohort from the Akershus study of chronic headache. Pain. 2012;153(3):682-686

123. Fuh JL, Wang SJ, Lu SR, Juang KD. Does medication overuse headache represent a behavior of dependence? Pain . 2005;119(1-3): 49-55. 
124. Radat F, Creac'h C, Guegan-Massardier E, et al. Behavioral dependence in patients with medication overuse headache: a cross-sectional study in consulting patients using the DSM-IV criteria. Headache. 2008;48(7):1026-1036.

125. Lauwerier E, Paemeleire K, Van Damme S, Goubert L, Crombez G. Medication use in patients with migraine and medication-overuse headache: the role of problem-solving and attitudes about pain medication. Pain. 2011;152(6):1334-1339.

126. Galli F, Pozzi G, Frustaci A, et al. Differences in the personality profile of medication-overuse headache sufferers and drug addict patients: a comparative study using MMPI-2. Headache. 2011;51(8):1212-1227.

127. Sances G, Galli F, Anastasi S, et al. Medication-overuse headache and personality: a controlled study by means of the MMPI-2. Headache. 2010;50(2):198-209.

128. Ferrari A, Cicero AF, Bertolini A, Leone S, Pasciullo G, Sternieri E. Need for analgesics/drugs of abuse: a comparison between headache patients and addicts by the Leeds Dependence Questionnaire (LDQ). Cephalalgia. 2006;26(2):187-193.

129. Jonsson P, Jakobsson A, Hensing G, Linde M, Moore CD, Hedenrud T. Holding on to the indispensable medication - a grounded theory on medication use from the perspective of persons with medication overuse headache. J Headache Pain. 2013;14(1):43.

130. Saper JR, Hamel RL, Lake III AE. Medication overuse headache (MOH) is a biobehavioural disorder. Cephalalgia. 2005;25(7): 545-546.

131. Fuh JL, Wang SJ. Dependent behavior in patients with medicationoveruse headache. Curr Pain Headache Rep. 2012;16(1):73-79.

132. Radat F, Lanteri-Minet M. What is the role of dependence-related behavior in medication-overuse headache? Headache. 2010;50(10): 1597-1611.

133. Rossi P, Faroni JV, Nappi G. Short-term effectiveness of simple advice as a withdrawal strategy in simple and complicated medication overuse headache. Eur J Neurol. 2011;18(3):396-401.

134. Diener HC. Detoxification for medication overuse headache is not necessary. Cephalalgia. 2012;32(5):423-427.

135. Olesen J. Detoxification for medication overuse headache is the primary task. Cephalalgia. 2012;32(5):420-422.

136. Hagen K, Albretsen C, Vilming ST, et al. Management of medication overuse headache: 1-year randomized multicentre open-label trial Cephalalgia. 2009;29(2):221-232.

137. Linton-Dahlöf P, Linde M, Dahlöf C. Withdrawal therapy improves chronic daily headache associated with long-term misuse of headache medication: a retrospective study. Cephalalgia. 2000;20(7):658-662.

138. Katsarava Z, Fritsche G, Muessig M, Diener HC, Limmroth V. Clinical features of withdrawal headache following overuse of triptans and other headache drugs. Neurology. 2001;57(9):1694-1698.

139. Krymchantowski AV, Moreira PF. Out-patient detoxification in chronic migraine: comparison of strategies. Cephalalgia. 2003;23(10):982-993.

140. Grazzi L, Andrasik F, Usai S, Bussone G. In-patient vs day-hospital withdrawal treatment for chronic migraine with medication overuse and disability assessment: results at one-year follow-up. Neurol Sci. 2008;29 Suppl 1:S161-S163.

141. Creac'h C, Frappe P, Cancade M, et al. In-patient versus out-patient withdrawal programmes for medication overuse headache: a 2-year randomized trial. Cephalalgia. 2011;31(11):1189-1198.

142. Gaul C, Bromstrup J, Fritsche G, Diener HC, Katsarava Z. Evaluating integrated headache care: a one-year follow-up observational study in patients treated at the Essen headache centre. BMC Neurol. 2011;11:124.

143. Boe MG, Mygland A, Salvesen R. Prednisolone does not reduce withdrawal headache: a randomized, double-blind study. Neurology. 2007;69(1):26-31.

144. Rabe K, Pageler L, Gaul C, et al. Prednisone for the treatment of withdrawal headache in patients with medication overuse headache: a randomized, double-blind, placebo-controlled study. Cephalalgia. 2013;33(3):202-207.
145. Hagen K, Jensen R, Boe MG, Stovner LJ. Medication overuse headache: a critical review of end points in recent follow-up studies. J Headache Pain. 2010;11(5):373-377.

146. Grande RB, Aaseth K, Benth JS, Lundqvist C, Russell MB. Reduction in medication-overuse headache after short information. The Akershus study of chronic headache. Eur J Neurol. 2011;18(1): 129-137.

147. Rossi P, Di LC, Faroni J, Cesarino F, Nappi G, Di Lorenzo C. Advice alone vs structured detoxification programmes for medication overuse headache: a prospective, randomized, open-label trial in transformed migraine patients with low medical needs. Cephalalgia. 2006;26(9):1097-1105.

148. Rossi P, Faroni JV, Tassorelli C, Nappi G. Advice alone versus structured detoxification programmes for complicated medication overuse headache $(\mathrm{MOH})$ : a prospective, randomized, open-label trial. J Headache Pain. 2013;14(1):10.

149. Tassorelli C, Jensen R, Allena M, et al. A consensus protocol for the management of medication-overuse headache: evaluation in a multicentric, multinational study. Cephalalgia. Epub 2014 February 20.

150. Diener HC, Dodick DW, Goadsby PJ, et al. Utility of topiramate for the treatment of patients with chronic migraine in the presence or absence of acute medication overuse. Cephalalgia. 2009;29(10): 1021-1027.

151. Diener HC, Dodick DW, Aurora SK, et al. OnabotulinumtoxinA for treatment of chronic migraine: results from the double-blind, randomized, placebo-controlled phase of the PREEMPT 2 trial. Cephalalgia. 2010;30(7):804-814.

152. Aurora SK, Dodick DW, Turkel CC, et al. OnabotulinumtoxinA for treatment of chronic migraine: results from the double-blind, randomized, placebo-controlled phase of the PREEMPT 1 trial. Cephalalgia. 2010;30(7):793-803.

153. Sandrini G, Perrotta A, Tassorelli C, et al. Botulinum toxin type-A in the prophylactic treatment of medication-overuse headache: a multicenter, double-blind, randomized, placebo-controlled, parallel group study. J Headache Pain. 2011;12(4):427-433.

154. Silberstein SD, Blumenfeld AM, Cady RK, et al. OnabotulinumtoxinA for treatment of chronic migraine: PREEMPT 24-week pooled subgroup analysis of patients who had acute headache medication overuse at baseline. J Neurol Sci. 2013;331(1-2):48-56.

155. Sarchielli P, Messina P, Cupini LM, et al. Sodium valproate in migraine without aura and medication overuse headache: a randomized controlled trial. Eur Neuropsychopharmacol. Epub 2014 April 5.

156. Zeeberg P, Olesen J, Jensen R. Discontinuation of medication overuse in headache patients: recovery of therapeutic responsiveness. Cephalalgia. 2006;26(10):1192-1198.

157. Martelletti P, Jensen RH, Antal A, et al. Neuromodulation of chronic headaches: position statement from the European Headache Federation. J Headache Pain. 2013;14(1):86.

158. Freeman JA, Trentman TL. Clinical utility of implantable neurostimulation devices in the treatment of chronic migraine. Med Devices (Auckl). 2013;6:195-201.

159. Boe MG, Salvesen R, Mygland A. Chronic daily headache with medication overuse: a randomized follow-up by neurologist or PCP. Cephalalgia. 2009;29(8):855-863.

160. Grazzi L, Andrasik F, D’Amico D, Usai S, Kass S, Bussone G. Disability in chronic migraine patients with medication overuse: treatment effects at 1-year follow-up. Headache. 2004;44(7): 678-683.

161. Katsarava Z, Limmroth V, Finke M, Diener HC, Fritsche G. Rates and predictors for relapse in medication overuse headache: a 1-year prospective study. Neurology. 2003;60(10):1682-1683.

162. Katsarava Z, Muessig M, Dzagnidze A, Fritsche G, Diener HC, Limmroth V. Medication overuse headache: rates and predictors for relapse in a 4-year prospective study. Cephalalgia. 2005;25(1): $12-15$.

163. Zidverc-Trajkovic J, Pekmezovic T, Jovanovic Z, et al. Medication overuse headache: clinical features predicting treatment outcome at 1-year follow-up. Cephalalgia. 2007;27(11):1219-1225. 
164. Boe MG, Salvesen R, Mygland A. Chronic daily headache with medication overuse: predictors of outcome 1 year after withdrawal therapy. Eur J Neurol. 2009;16(6):705-712.

165. Rossi P, Faroni JV, Nappi G. Medication overuse headache: predictors and rates of relapse in migraine patients with low medical needs. A 1-year prospective study. Cephalalgia. 2008;28(11):1196-1200.

166. Andrasik F, Grazzi L, Usai S, Kass S, Bussone G. Disability in chronic migraine with medication overuse: treatment effects through 5 years. Cephalalgia. 2010;30(5):610-614.
167. Ghiotto N, Sances G, Galli F, et al. Medication overuse headache and applicability of the ICHD-II diagnostic criteria: 1-year follow-up study (CARE I protocol). Cephalalgia. 2009;29(2):233-243.

168. Lai JT, Dereix JD, Ganepola RP, et al. Should we educate about the risks of medication overuse headache? J Headache Pain. 2014;15:10.

169. Fritsche G, Frettloh J, Huppe M, et al. Prevention of medication overuse in patients with migraine. Pain. 2010;151(2):404-413.

\section{Publish your work in this journal}

The Journal of Pain Research is an international, peer-reviewed, open access, online journal that welcomes laboratory and clinical findings in the fields of pain research and the prevention and management of pain. Original research, reviews, symposium reports, hypothesis formation and commentaries are all considered for publication.

\section{Dovepress}

The manuscript management system is completely online and includes a very quick and fair peer-review system, which is all easy to use. Visit http://www.dovepress.com/testimonials.php to read real quotes from published authors. 